\title{
Knocking out Analysis of the CpxP gene using Crispr/Cas9 in Escherichia coli MG1655
}

\author{
Xiaoliang He $\mathbb{0}$, Yuwen Ren, Wanli Meng, Xinran Yu and Xiaohui Zhou*
}

\begin{abstract}
Based on the analysis of cpxP genes among Escherichia coli strains, cpxP gene-targeting short guide RNA (sgRNA) was designed and inserted into the pGL3-MGP-RNA. The donor sequences (MG-HR) for homologous repair were designed and cloned by PCR. MG-HR and pGL3-MGP-RNA were transformed into E. coli MG1655 (pCas9). The cpxP gene expression cassette was amplified by PCR and subcloned into pBBR1MCS-2. Then the pBBR-cpxP was independently transformed into E. coli MG1655. The results of motility experiment suggest that cpxP gene had a significant effect on the movement ability of E. coli strain. The CpxP protein had a significant inhibition of bacterial activity. The lastest 81 CpxP proteins sequences were selected and analyzed by multi-sequence alignment and molecular cluster. The CpxP proteins were roughly divided into three categories. Our results suggest that the CpxP protein was involved in bacterial motility, infection and pathogenicity.
\end{abstract}

Keywords: Knocked out, cpxP, Crispr/Cas9, Homologous repair, Escherichia coli

\section{Key points}

The E. coli MG1655- $\Delta c p x P$ were successfully obtained.

The $\operatorname{cpxP}$ gene had a significant effect on the movement ability of $E$. coli strain.

The CpxP proteins had a significant inhibition of bacterial activity.

\section{Introduction}

The Cpx system is one of the most common two-component regulatory systems in Gram-negative bacteria. It consists of the membrane-anchored sensor kinase CpxA, the cytosolic response regulator CpxR, and the peripheral spatial helper protein CpxP (Dong et al. 1993; Ruiz and Silhavy 2005). The CpxP proteins can inhibit activation of CpxA and are indispensable for the quality control system of $\mathrm{P}$ pili that are protein filaments expressed by uropathogenic Escherichia coli (Fällman et al. 2005; Nevesinjac and Raivio 2005). The structure of CpxP was interdigitated with two monomers like "left hands" forming a cap-shaped dimer. The structure revealed an

\footnotetext{
*Correspondence: zhouxh2003@aliyun.com

School of Biological Science and Engineering, Hebei University of Science and Technology, No. 26 Yuxiang Street, Shijiazhuang 050018, Hebei, China
}

antiparallel dimer of intertwined $\alpha$-helices with a highly basic concave surface (Thede et al. 2011). The CpxP proteins inhibit the kinase CpxA through direct interaction between its concave polar surface and the negatively charged sensor domain on CpxA (Zhou et al. 2011).

The CRISPR-Cas system was used recently as efficient genome engineering technology in several prokaryotes and eukaryotes, including (but not limited to) Escherichia coli (Jiang et al. 2013), Saccharomyces cerevisiae (DiCarlo et al. 2013), yeast (DiCarlo et al. 2015), Streptomyces spp. (Cobb et al. 2014), higher plants (Shan et al. 2013), Bombyx mori (Wang et al. 2013), Drosophila (Yu et al. 2013), insects (Gantz and Bier 2015), Anopheles stephensi (Gantz et al. 2015), Anopheles gambiae (Hammond et al. 2016), mouse (Grunwald et al. 2019) and human cell lines (Cong et al. 2013; Mali et al. 2013; Zhang et al. 2013). The CRISPR/Cas9 system was also used to remove plasmid harbouring mcr-1 from Escherichia coli (Dong et al. 2019).

This study constructed an expression vector pGL3MGP-RNA including gene-targeting short guide RNA and cloned a donor sequences (MG-HR) for homologous repair. The cell-envelope stress modulator $c p x P$ gene of MG1655 strain was successfully knocked out
Springer Open (c) The Author(s) 2020. This article is licensed under a Creative Commons Attribution 4.0 International License, which permits use, sharing, adaptation, distribution and reproduction in any medium or format, as long as you give appropriate credit to the original author(s) and the source, provide a link to the Creative Commons licence, and indicate if changes were made. The images or other third party material in this article are included in the article's Creative Commons licence, unless indicated otherwise in a credit line to the material. If material is not included in the article's Creative Commons licence and your intended use is not permitted by statutory regulation or exceeds the permitted use, you will need to obtain permission directly from the copyright holder. To view a copy of this licence, visit http://creativeco mmons.org/licenses/by/4.0/. 
by CRISPR-Cas9 system-based gene editing strategy. Likewise, the system can efficiently edit a large plasmid, target genes on the bacterial chromosome, or be adapted to introduce functional gene cargos alongside the gRNA cassette.

\section{Materials and methods Plasmid construction}

The pCas9 and pGL3-U6-SgRNA-PGK-Puromycin Plasmid (Youbio, Hunan, China) was extracted from $E$. coli $\mathrm{DH} 5 \alpha$ by Plasmid extraction kit (GenStar, Beijing, China). The pCas9 Plasmid was transfected into E. coli MG1655 (Tiangen, Beijing, China) to acquire E. coli MG1655 (pCas9). The transformed E. coli MG1655 was screened using Kanamycin $(50 \mathrm{mg} / \mathrm{L})$ that was added to the LB medium. Genomic DNA was extracted from $E$. coli MG1655 by Bacterial genome extraction kit (GenStar, Beijing, China).

The MG-HR-S and MG-HR-X were amplified by PCR using the genomic DNA as a template. The primers were designed with prime primer 5.0. The primers were synthesized by the Beijing Invitrogen Biotechnology Company. The primers TCTGGTGTGTCTGGC GAAGT and TGCTAATTCGTGGAGCTTATGCCA GCG TTGAGGCCATG were used to amplify MG-HRS. The primers TAAGCTCCACGAATTAGCATCAGC AGATGCGAGATCTTAT and CTATGGC AAGGAA AACAGGGT were used to amplify MG-HR-X. MGHR-S was connected to MG-HR-X by PCR to acquire a MG-HR.

The MGP-sgRNA and pGL3 were amplified by PCR using the pGL3-U6-SgRNA-PGK-Puromycin Plasmid as a template.

The primers CGGGATCCTTGACAGCTAGCT CAGTCCTAGGTATAATACTAG TTCAGGCGATAA CTGGCATCCGTTTTAGAGCTAGAAAT and GGG GTACCGG AACCACGCCCAGAGCAG were used to amplify MGP-sgRNA.

The primers GGGGTACCGCTCACTGACTCGCTG CGCT and CGGGATCCGC TTAATGCGCCGCTAC AGG were used to amplify pGL3.

The $c p x P$ gene expression cassette comprising said promoter, a $c p x P$ gene and said terminator was amplified by PCR using the genomic DNA as a template.

\section{cpxP-F:}

CTGCC $3^{\prime}$

cpxP-R: CGCGGATCCAGACAGGGATGGTGTCTA TGGC $3^{\prime}$

The PCR was carried out by using the Gene Amp PCR system 9700 (Applied Biosystems). PCR products were confirmed on $1.0 \%$ agarose gels and recycled by the agarose gel extraction kit (Macherey-Nagel, Germany).
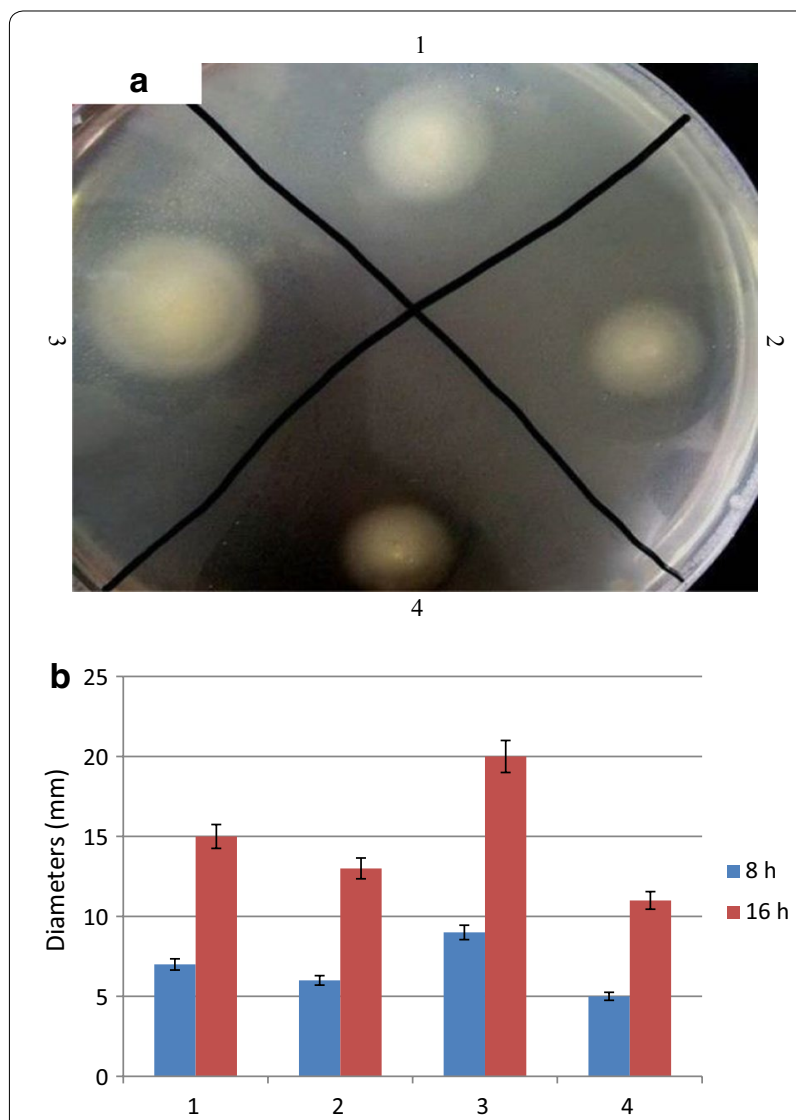

Fig. 1 a Motility experiment of the strains. (1) Motility experiment of E. coli MG1655. (2) Motility experiment of the revertants. (3) Motility experiment of E. coli MG1655- $\triangle c p x P$. (4) Motility experiment of the overexpression transformants. $\mathbf{b}$ Diameters of the strains in the LB semi-solid medium for $8 \mathrm{~h}$ and 16 h. (1) Diameters of E. coli MG1655. (2) Diameters of the revertants. (3) Diameters of E. coli MG1655- $\triangle$ cpxP. (4) Diameters of the overexpression transformants. Values are the mean $\pm S D(n=5)$

\section{Transformation of recombinant plasmid}

Recycled PCR products of the MGP-sgRNA and pGL3 were digested by KpnI and BamHI (Thermo Fisher, USA), and then connected by T4 DNA Ligase (Thermo Fisher, USA) to acquire a pGL3-MGP-sgRNA.

$400 \mu \mathrm{g}$ pGL3-U6-sgRNA-PGK-puromycin, $400 \mu \mathrm{g}$ pGL3-MGP-RNA, $400 \mu \mathrm{g}$ pGL3-MGP-RNA and $1.6 \mu \mathrm{g}$ MG-HR were separately transformed into $E$. coli MG1655 (pCas9). The transformed E. coli MG1655 (pCas9) were screened using Kanamycin $(50 \mathrm{mg} / \mathrm{L})$ and Ampicillin $(100 \mathrm{mg} / \mathrm{L})$ that were added to the $\mathrm{LB}$ medium.

Recycled PCR products of the $c p x P$ gene expression cassette were digested by BamHI and HindIII (Thermo Fisher, USA), purified by the agarose gel extraction kit. The purified PCR products were directly subcloned 


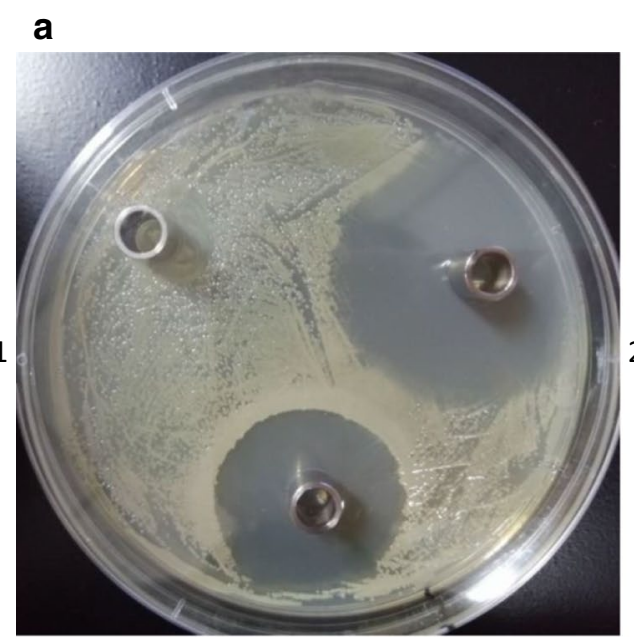

3

\section{b}

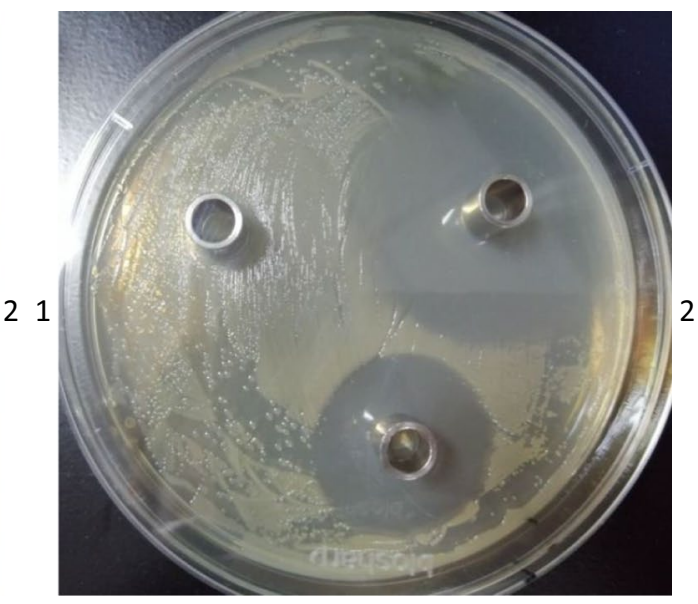

3

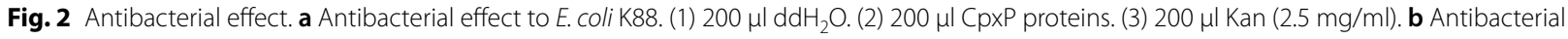

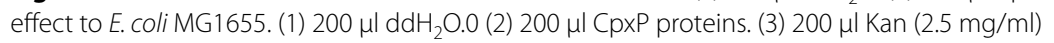

Table 1 Inhitory circle of CpxP after dispersed to two kinds of pathogen vobrio

\begin{tabular}{lll}
\hline & \multicolumn{2}{l}{ Inhibitory circle $(\mathbf{m m})$} \\
\cline { 2 - 3 } & E. coli $\mathbf{~ K 8 8}$ & E. coli MG1655 \\
\hline $\mathrm{ddH}_{2} \mathrm{O}$ & 0 & 0 \\
$\mathrm{CpxP}$ proteins & $27 \pm 1.15$ & $29 \pm 1.25$ \\
$\mathrm{Kan}$ & $37 \pm 1.23$ & $34 \pm 1.19$ \\
\hline
\end{tabular}

Values are the mean $\pm S D(n=4)$

into pBBR1MCS-2 (Youbio, Hunan, China) (No. pBBR-cp $x P$ ). Then the pBBR-cpxP was independently transformed into E. coli MG1655 to acquire the overexpression transformants and E. coli MG1655- $\Delta c p x P$ to acquire a revertant. The transformed $E$. coli MG1655 were screened using Kanamycin $(50 \mathrm{mg} / \mathrm{L})$.

\section{Motility experiment}

Escherichia coli MG1655, overexpression transformants, the knocked out mutants and revertants were inoculumned on LB medium for overnight. Then the cultures $(2 \mu \mathrm{l})$ were added to the LB semi-solid medium for overnight.

\section{Bacteriostatic experiment}

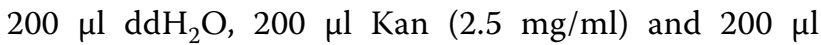
CpxP proteins $(8 \mathrm{mg} / \mathrm{ml})$ were independently added to the LB solid medium by $6 \mathrm{~mm}$ Oxford cup containing $100 \mu \mathrm{l}$ E. coli MG1655 and E. coli K88 $\left(10^{5} \mathrm{cfu} /\right.$ ml) for $16 \mathrm{~h}$ at $4{ }^{\circ} \mathrm{C}$. Then they were kept at $37^{\circ} \mathrm{C}$ for bacteriostatic experiment.

\section{Molecular clustering}

To evaluate and analyze CpxP sequence resource preliminary, we had found $81 \mathrm{CpxP}$ sequences from public database (http://www.ncbi.nlm.nih.gov/) and done multi-sequence alignment and molecular cluster by Clustal X and Treeview (He et al. 2015).

\section{Results}

\section{Cloning of $c p x P$ gene fragment}

The $c p x P$ gene fragments were cloned by PCR using MG-HR-S-F and MG-HR-S-R, MG-HR-X-F and MGHR-X-R as primers. The results showed that the lengths of $c p x P$ gene fragment were $424 \mathrm{bp}$ and $377 \mathrm{bp}$ respectively. The lengths of MG-HR-S and MG-HR-X were 782 bp (Additional file 1: Figure S1).

\section{Identification of pGL3-MGP-sgRNA plasmid}

To confirm whether the MGP-sgRNA and pGL3 were connected by T4 DNA Ligase, the recombinant plasmids (pGL3-MGP-sgRNA) were digested with KpnI and BamHI. According to the electrophoresis, the recombinant plasmids (pGL3-MGP-sgRNA) were successfully obtained (Additional file 1: Figure S2).

\section{Identification of the knockout of $c p x P$ gene}

The knockout of $\operatorname{cx} x P$ gene was identified by PCR using MG-HR-S-F and MG-HR-X-R as primers, the genomic DNA of E. coli MG1655 (pCas9) as a template. According 


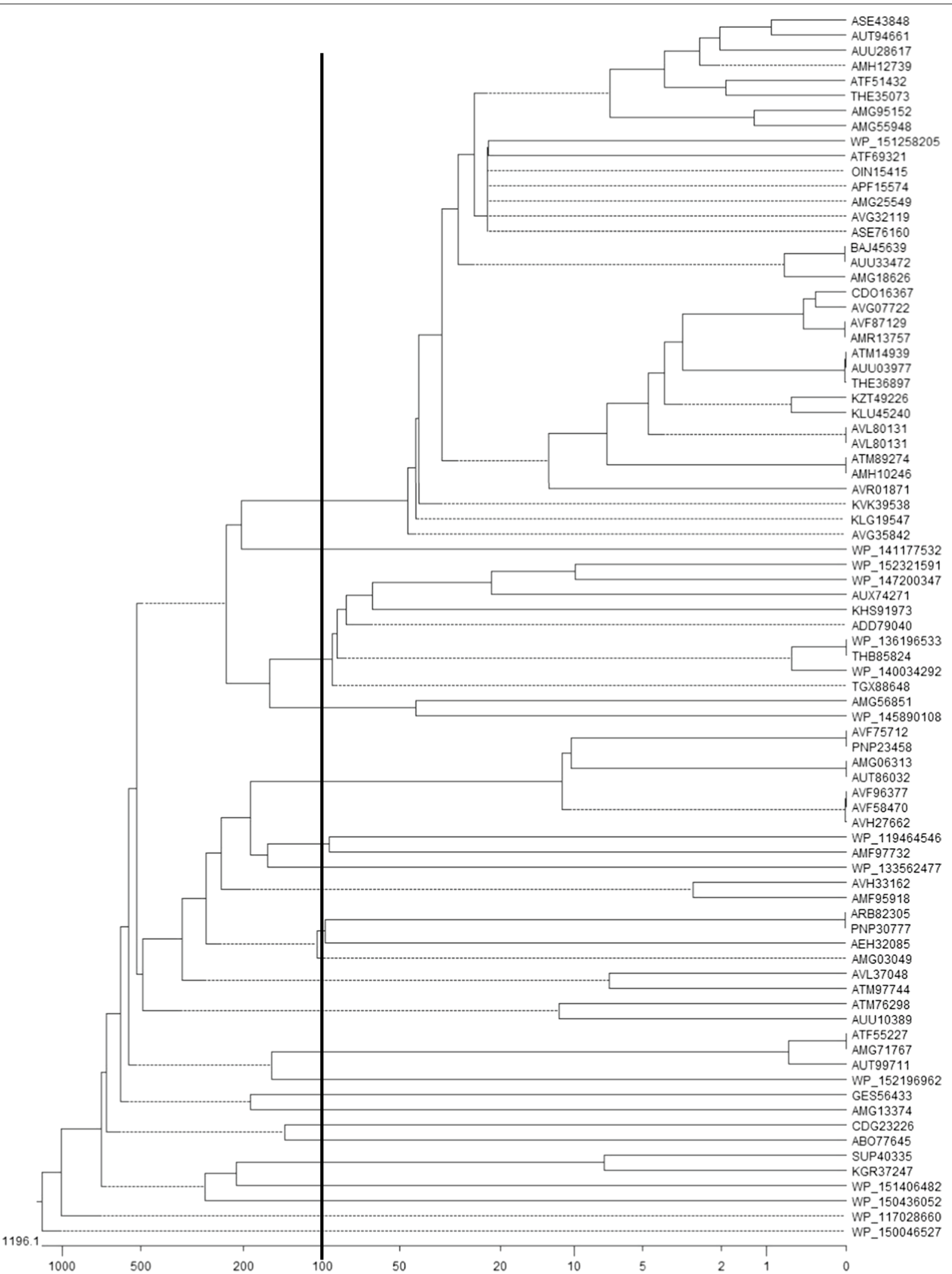

Fig. 3 Molecular cluster of 81 CpxP protein sequences from 8 microbial species by Clustal X and Treeview 
to the electrophoresis, the lengths of PCR products were 888 bp without knockout and 782 bp after knockout of $\operatorname{cpxP}$ gene (Additional file 1: Figure S3A). The PCR products were sent to the Beijing Invitrogen Biotechnology Company for sequencing. The sequences were done multi-sequence alignment by DNAstar (Additional file 1: Figure S3B). These results suggest that the $E$. coli MG1655- $\Delta c p x P$ were successfully obtained.

\section{Identification of pBBR-cpxP plasmid}

PCR products of the $c p x P$ gene expression cassette were digested by BamHI and HindIII, and cloned into pBBR1MCS-2. According to the electrophoresis, the recombinant plasmids (pBBR1MCS-2), the overexpression transformants and revertant were successfully obtained (Additional file 1: Figure S4).

\section{Motility experiment}

Many studies have confirmed that the motility of bacteria plays an important role in the pathogenicity of bacteria during the early interaction with the host. To investigate the effect of the $c_{x x P}$ gene on the motility of E. coli, the mobility of the strain was determined. The results showed that the diffusion diameters of E. coli MG1655$\triangle c p x P$ is significantly greater than $E$. coli MG1655 (Student's t-test, $\mathrm{P}<0.05$ ) (Fig. 1). The diffusion diameters of the overexpression transformants are significantly smaller than E. coli MG1655 (Student's t-test, $\mathrm{P}<0.05$ ). These results suggest that $c p x P$ gene had a significant effect on the movement ability of $E$. coli strain.

\section{Bacteriostatic experiment}

To investigate the affect of the CpxP proteins on the antibacterial, the diameters of inhibition zone were determined. The results (Fig. 2) showed that the inhibition effect of CpxP proteins was significantly greater than $\mathrm{ddH}_{2} \mathrm{O}$ (Student's t-test, $\mathrm{P}<0.01$ ), and there was significant difference compared with Kan (Student's t-test, $\mathrm{P}<0.05)$ (Table 1 ). These results suggest that CpxP proteins had a significant inhibition of bacterial activity.

\section{Molecular clustering}

Multi-sequence alignment and molecular cluster was carried out for $81 \mathrm{CpxP}$ proteins sequences. The results indicated that $\mathrm{CpxP}$ were roughly divided into three categories (Fig. 3). The protein sequence of the E. coli CpxP (BAJ45639) exhibited 100\%, 100\% and 89.2\% homology with the Shigella flexneri (AUU33472), Shigella sonnei (AMG18626) and Salmonella enterica (AMG25549) homologous proteins, respectively. All the bacterial names corresponding to the gi numbers and sequences were showed (Additional file 1: Table S1).

\section{Discussion}

The cell-envelope stress modulator $c p x P$ (periplasmic protein) gene has been investigated for many years, but there are few studies on its function. The CpxP proteins can inhibit activation of CpxA and are indispensable for the quality control system of $P$ pili.

In this report, the results showed that the $c p x P$-overexpression $E$. coli MG1655, the knocked out mutants $E$. coli MG1655- $\triangle c p x P$ and the revertants E. coli MG1655$\triangle c p x P$ (pBBR-cpxP) were obtained. Deprivation of the cpxP gene resulted in significant enhancement in the mobility of E. coli strains. The overexpression of the $\operatorname{cpxP}$ gene also resulted in significant attenuation in the mobility of $E$. coli strains. The mobility of $E$. coli revertants strains was lower than E. coli MG1655. The mobility of bacteria had important pathological significance, moreover, and mainly played its role during the early stage of the infection (Mao and He 1998). In an experimental urinary tract infection of the mouse, colonization of the urinary bladder by isogenic strains of Salmonella enterica serovar Typhimurium was found to depend on the motility of the bacteria (Siitonen and Nurminen 1992). Our results suggest that the deprivation of the $\operatorname{cpxP}$ gene resulted in significant enhancement in the mobility and infection of E. coli strains.

Multi-sequence alignment and molecular cluster indicated that the CpxP proteins had a high homology at protein level with Shigella flexneri, Shigella sonnei and Salmonella enteric which are the main pathogenic bacteria in China. Our results suggest that the overexpressions of the $\operatorname{cpxP}$ gene may significantly reduce the pathogenicity of these bacteria.

\section{Supplementary information}

Supplementary information accompanies this paper at https://doi. org/10.1186/s13568-020-01099-z.

Additional file 1. The electrophoregram and sequences of cpxP.

Acknowledgements

The research was supported by Natural Science Foundation of China (Nos. 31100044, 31270077), "100 Talent Program" of Hebei Province (No. E2012100005), Scientific Research Foundation for the Returned Overseas Chinese Scholars (1792-47) and Hebei Provincial Natural Science Fund (No. C2014208093, 17223608D, Key Project No. C2020208020).

\section{Authors' contributions}

$X H$ and $X Z$ conceived and designed research. $Y R$, WM and $X Y$ conducted experiments. $X Z$ contributed the reagents. $\mathrm{XH}$ and $\mathrm{YR}$ analyzed data. $\mathrm{XH}$ wrote the manuscript. All authors read and approved the final manuscript.

Funding

Not applicable. 
Availability of data and materials

Not applicable.

\section{Ethics approval and consent to participate}

Not applicable.

\section{Consent for publication}

Not applicable.

\section{Competing interests}

All authors declare that he has no conflict of interest.

Received: 19 May 2020 Accepted: 27 August 2020

Published online: 26 September 2020

\section{References}

Cobb RE, Wang Y, Zhao H (2014) High-efficiency multiplex genome editing of Streptomyces species using an engineered CRISPR/Cas system. ACS Synth Biol. 4(6):723-728

Cong L, Ran FA, Cox D, Lin S, Barretto R, Habib N, Hsu PD, Wu X, Jiang W, Marraffini LA, Zhang F (2013) Multiplex genome engineering using CRISPR/ Cas systems. Science 339:819-823

DiCarlo JE, Norville JE, Mali P, Rios X, Aach J, Church GM (2013) Genome engineering in Saccharomyces cerevisiae using CRISPR-Cas systems. Nucleic Acids Res 41:4336-4343

DiCarlo JE, Chavez A, Dietz SL, Esvelt KM, Church GM (2015) Safeguarding CRISPR-Cas9 gene drives in yeast. Nat Biotechnol 33:1250-1255

Dong J, luchi S, Kwan HS, Lu Z, Lin ECC (1993) The deduced amino-acid sequence of the cloned CpxR gene suggests the protein is the cognate regulator for the membrane sensor, CpxA, in a two-component signal transduction system of Escherichia coli. Gene 136(1):227-230

Dong $H$, Xiang H, Mu D, Wang D, Wang T (2019) Exploiting a conjugative CRISPR/Cas9 system to eliminate plasmid harbouring the mcr-1 gene from Escherichia coli. Int J Antimicrob Agents 53(1):1-8

Fällman E, Schedin S, Jass J, Uhlin BE, Axner O (2005) The unfolding of the $p$ pili quaternary structure by stretching is reversible, not plastic. EMBO Rep 6(1):52-56

Gantz VM, Bier E (2015) The mutagenic chain reaction: a method for converting heterozygous to homozygous mutations. Science 348:442-444

Gantz VM, Jasinskiene N, Tatarenkova O, Fazekas A, James AA (2015) Highly efficient Cas9-mediated gene drive for population modification of the malaria vector mosquito Anopheles stephensi. Proc Natl Acad Sci USA 112:E6736-E6743

Grunwald HA, Gantz VM, Poplawski G, Xu XS, Bier E, Cooper KL (2019) SuperMendelian inheritance mediated by CRISPR-Cas 9 in the female mouse germline. Nature 566:105-109
Hammond A, Galizi R, Kyrou K, Simoni A, Siniscalchi C, Katsanos D (2016) A CRISPR-Cas9 gene drive system targeting female reproduction in the malaria mosquito vector Anopheles gambiae. Nat Biotechnol 34:78-83

He XL, Zhou XH, Yang Z, Xu L, Yu YX, Jia LL, Li GQ (2015) Cloning, expression and purification of d-tagatose 3-epimerase gene from Escherichia coli JM109. Protein Expres Purif. 114:77-81

Jiang W, Bikard D, Cox D, Zhang F, Marraffini LA (2013) RNA-guided editing of bacterial genomes using CRISPR-Cas systems. Nat Biotechnol 31:233-239

Mali P, Yang L, Esvelt KM, Aach J, Guell M, DiCarlo JE, Norville JE, Church GM (2013) RNA-guided human genome engineering via Cas9. Science 339:823-826

Mao GZ, He LY (1998) Relationship of wild type strain motility and interaction with host plants in Ralstonia solanacearum. Bacterial wilt disease Springer, Berlin, pp 184-191

Nevesinjac AZ, Raivio TL (2005) The cpx envelope stress response affects expression of the type iv bundle-forming pili of enteropathogenic Escherichia coli. J Bacteriol 187(2):672-686

Ruiz N, Silhavy TJ (2005) Sensing external stress: watchdogs of the Escherichia coli cell envelope. Curr Opin Microbiol 8:122-126

Shan Q, Wang Y, Li J, Zhang Y, Chen K, Liang Z, Zhang K, Liu J, Xi JJ, Qiu JL, Gao C (2013) Targeted genome modification of crop plants using a CRISPRCas system. Nat Biotechnol 31:686-688

Siitonen A, Nurminen M (1992) Bacterial motility is a colonization factor in experimental urinary tract infection. Infect Immun 60(9):3918-3920

Thede GL, Arthur DC, Edwards RA, Buelow DR, Wong JL, Raivio TL (2011) Structure of the periplasmic stress response protein CpxP. J Bacteriol 193(9):2149-2157

Wang Y, Li Z, Xu J, Zeng B, Ling L, You L, Chen Y, Huang Y, Tan A (2013) The CRISPR/Cas System mediates efficient genome engineering in Bombyx mori. Cell Res 23:1414-1416

Yu Z, Ren M, Wang Z, Zhang B, Rong YS, Jiao R, Gao G (2013) Highly efficient genome modifications mediated by CRISPR/Cas9 in Drosophila. Genetics 195:289-291

Zhang Q, Rho M, Tang H, Doak TG, Ye Y (2013) CRISPR-Cas systems target a diverse collection of invasive mobile genetic elements in human microbiomes. Genome Biol 14:R40

Zhou X, Keller R, Volkmer R (2011) Structural basis for two-component system inhibition and pilus sensing by the auxiliary CpxP protein. J Biol Chem 286(11):9805-9814

\section{Publisher's Note}

Springer Nature remains neutral with regard to jurisdictional claims in published maps and institutional affiliations.

\section{Submit your manuscript to a SpringerOpen ${ }^{\circ}$ journal and benefit from:}

- Convenient online submission

- Rigorous peer review

- Open access: articles freely available online

- High visibility within the field

- Retaining the copyright to your article

Submit your next manuscript at springeropen.com 